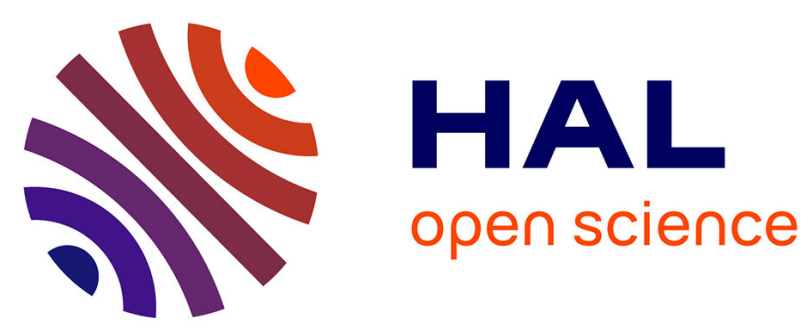

\title{
CARV2007 Special Issue:A STRUCTURED AGILE DESIGN APPROACH TO SUPPORT CUSTOMISATION IN WELLNESS PRODUCT DEVELOPMENT
}

Michele Germani, Maura Mengoni, Ferruccio Mandorli

\section{To cite this version:}

Michele Germani, Maura Mengoni, Ferruccio Mandorli. CARV2007 Special Issue:A STRUCTURED AGILE DESIGN APPROACH TO SUPPORT CUSTOMISATION IN WELLNESS PRODUCT DEVELOPMENT. International Journal of Computer Integrated Manufacturing, 2009, 22 (01), pp.42-54. 10.1080/09511920802326233 . hal-00513405

\section{HAL Id: hal-00513405 https://hal.science/hal-00513405}

Submitted on 1 Sep 2010

HAL is a multi-disciplinary open access archive for the deposit and dissemination of scientific research documents, whether they are published or not. The documents may come from teaching and research institutions in France or abroad, or from public or private research centers.
L'archive ouverte pluridisciplinaire HAL, est destinée au dépôt et à la diffusion de documents scientifiques de niveau recherche, publiés ou non, émanant des établissements d'enseignement et de recherche français ou étrangers, des laboratoires publics ou privés. 


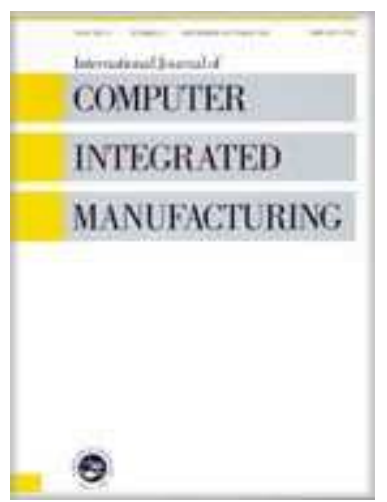

\section{CARV2007 Special Issue:A STRUCTURED AGILE DESIGN APPROACH TO SUPPORT CUSTOMISATION IN WELLNESS PRODUCT DEVELOPMENT}

\begin{tabular}{|c|c|}
\hline Journal: & International Journal of Computer Integrated Manufacturing \\
\hline Manuscript ID: & TCIM-2007-IJCIM-0103.R1 \\
\hline Manuscript Type: & Special Issue Paper \\
\hline $\begin{array}{r}\text { Date Submitted by the } \\
\text { Author: }\end{array}$ & 18 -Jun-2008 \\
\hline Complete List of Authors: & $\begin{array}{l}\text { Germani, Michele; Università Politecnica delle Marche, Department } \\
\text { of Mechanics } \\
\text { Mengoni, Maura; Università Politecnica delle Marche, Department of } \\
\text { Mechanics } \\
\text { Mandorli, Ferruccio; Università Politecnica delle Marche, } \\
\text { Department of Mechanics }\end{array}$ \\
\hline Keywords: & $\begin{array}{l}\text { AGILE MANUFACTURING, INJECTION MOULDING, MASS } \\
\text { CUSTOMIZATION }\end{array}$ \\
\hline Keywords (user): & AGILE DESIGN, PRODUCT CUSTOMISATION \\
\hline
\end{tabular}

\section{今 ScholaroNE \\ Manuscript Central}




\title{
A STRUCTURED AGILE DESIGN APPROACH TO SUPPORT CUSTOMISATION IN WELLNESS PRODUCT DEVELOPMENT
}

\author{
Maura Mengoni, Michele Germani, Ferruccio Mandorli \\ Department of Mechanics \\ Faculty of Engineering, Polytechnic University of Marche \\ 60131, Via Brecce Bianche \\ Ancona, Italy
}

Tel. Int +39712204969 (or 2204790)

Fax Int +3971 2204801

E-mailm.germani@univpm.it

URL: http://www.dipmec.univpm.it 


\section{ABSTRACT}

The global market is evermore volatile and turbulent; it requires rapid responses to the emerging customers needs, also to unpredictable ones. Companies are forced towards a continuous research and innovation in terms of flexible technologies and processes in order to provide a high level of market adaptability. In this context, agile approaches, intended as a set of strategies to face the market variability, have to be investigated. They have to interest all processes related to the product development phase. This paper is focused on how implement an efficient agile strategy in product design. The proposed approach is based on product modularity and on the integration of CAD-based tools to support feasibility analysis on virtual prototypes. It allows the concurrent management of possible changes in both product and process platforms by adopting virtual prototypes for performing simulations. The implemented platforms and the connected virtual prototype are structured according to modularity principles. The virtual prototype is defined as a collection of geometrical, functional, structural, manufacturing, environmental information, contained in the modules of the product and process platforms.

An industrial example, belonging to the wellness production field (such as bathtubs and shower stalls), is described to validate the agile approach. It has been applied to solve a particularly meaningful problem: how to improve the bathtubs production process by reducing manufacturing and assembly costs while improving product customisability, ecosustainability and quality. Once analysed the context and the design constraints, in terms of cost, of environmental performance and, mainly, of aesthetic product features customization, it has been introduced a new manufacturing process based on the injection moulding technology instead of traditional thermoforming sheets.

Keywords: Agile Design, Aesthetic Product Development, Customisation, Injection Moulding 


\section{Introduction}

The today market globalization is a causal force of hypercompetition. The "hypercompetitive" market, (D'Aveni 1995), is an intense competitive environment where firms position themselves aggressively against one another and seek to disrupt the competitive advantages of the industry leaders. The reduction in price, the increase of quality, the functionalities and performances of products, processes and services and the continuous technological upgrade are some of the ways through which the impact of hypercompetitive challenges can be faced out. In parallel, shortening product life cycle time is imperative.

Simultaneously, due to the growing interest for the creation of a sustainable society, companies are seeking ways to reduce the environmental performance of products and processes while increasing their efficiency, by implementing life cycle oriented concepts to their decision-making process.

This context requires the study and implementation of new approaches and technologies to face the management of the whole product life cycle. Agility concepts address new ways of running companies to meet these challenges.

Agility requires the capability to survive and prosper in a competitive environment of continuous and unpredictable change by reacting quickly and effectively to changing markets, driven by customer-designed products and services (Gunasekaran and Yusuf 2002). The agile approach initially has been oriented towards the manufacturing problems as a vision of manufacturing that is a natural development from the original concept of lean manufacturing. The key enablers of agile manufacturing include: virtual enterprise tools, physically distributed manufacturing architecture and teams, rapid partnership formation tools, concurrent engineering; integrated product/production/business information system, rapid prototyping and electronic commerce (Gunasekaran 1998). As a consistent part of agile 
implementation efforts has been dedicated to the production and manufacturing management; the next goal is moving the focus on the product design phase studying agile design approaches that take into account the whole product life cycle.

The agile product design has been defined as the set of strategies and tools able to support the rapid reconfiguration of product and the related processes according to the emerging market requirements (Preiss et al. 1996). The main problem is to predict, assess and manage the impact of changes, along the whole product lifecycle, when new design solutions are introduced to face cost, time and environmental problems.

The key element of a successful agile product design is the definition of the modular product architecture that can be modelled in a virtual engineering framework. Well-designed modular product architecture can help the management of product changes and upgrades, product variety and component standardization (O'Grady 1999). In order to take into consideration the whole product life cycle, it is important to link the product platform with the manufacturing processes required to realize the physical parts and the modules assembly. This bi-directional link enables the prediction of the production phase changes in respect with product design modifications, and vice versa, and allows the identification of the modules affected by the variations.

In order to model the product and to simulate some aspects of its behaviour, several software tools can be used (CAD/CAM/FEA/CAE, etc.). However, in order to define a virtual engineering structure, the virtual prototype model must be fully integrated in a virtual framework able to represent, not only the different properties of the product, but also the context in which the product is manufactured, assembled and controlled.

In this scenario, a key problem is how to properly link the description of the product components and modules with the related manufacturing and assembly process description. 
This is the fundamental premise in order to identify which product parts are affected by changes, and to use simulations results to drive modifications.

In the proposed approach, this crucial issue is faced by enhancing the traditional definition of virtual prototype, mainly based on geometrical information, with a collection of non geometrical design information (i.e. functional, aesthetical, manufacturing parameters and constraints, environmental requirements, costs, structural performances), that allows a multiple level of product abstraction view.

In order to implement the structure able to represent all this type of information, it is necessary to increase and customise the set of information managed by the traditional computer based modelling and simulation tools.

The present paper is focused on the definition of the information management platform architecture, based on the concept of modularity and on the use of virtual prototypes.

The proposed method has been experimented in the wellness production field, for the development of a new bathtubs product line, with the intent to meet new customers needs and to satisfy several additional requirements concerning with aesthetics customisation and environmental performance.

The paper, after a brief review of agile product development approaches and the main issues in modularity, describes the system framework and the developed virtual engineering platform. Finally, the test case is illustrated and the design and manufacturing solution is discussed in order to validate the approach demonstrating the real advantages connected with its application.

\section{Background: strategies and tools to support the agile product development}

The product design activity can be defined as the transformation of explicit and tacit customer requirements in technical solutions. Information Technology (IT) can help to formalize, to 
represent, to manage and to store the information related to the design process. However, IT itself does not support the management of the teamwork dynamic nature and the rapid reconfiguration of product design and corresponding manufacturing processes once new emerging requirements or alternative solutions occur. The implementation of novel strategies and the integration of several IT tools are crucial for maintaining companies' competitiveness. Concurrent Engineering (CE), Virtual Enterprise (VE), Modularity, Supply-chain Integration are only some of the main strategies to implement Agility in the product development.

Concurrent engineering has been considered one of the key concepts that allow companies to improve product competitiveness by incorporating product life cycle values into the early stages of design (Chen et al. 1999): from conceptual design through manufacturing to disposal, including product functionality, cost, manufacturability, serviceability, and even recycleability (Feldhusen et al. 2006).

Agility can be considered as a new way of thinking the entire product life cycles, including design and manufacturing. Its implementation allows companies to give a rapid and flexible response to uncertain and unpredictable changes. Agility requires collaboration, integration of customers in the development chain, knowledge reuse and rapid configuration of product and processes (Mondragon et al. 2004).

Along the product design development several unpredictable events can occur, i.e. the late modification of the customer requirements or the excessive cost of a specific design solution. When an event appears, its impact has to be immediately evaluated and the product design has to be rapidly reconfigured, minimizing the propagation of consequences (Matthews et al. 2005).

In order to face these events, an agile design framework through a common distributed and collaborative environment is presented in (Lomas et al. 2006). The proposal is aligned to the Digital Enterprise Technology (DET) Framework (Maropoulos 2003). Digital tools and 
scenarios are set for enabling a faster response to unexpected events and a reduced product development cycle, integrating both IT and efficient management strategies.

Scenarios definition implies the classification of the unexpected events related to a product; in (Ye 2002) it is shown an example for architecting a structure of rules and modification tools able to solve the problem using the right resources without influencing the final time to market. The approach can be successfully applied if products are redesigned in terms of modularity and configurability for offering individually customized goods.

The implementation of modularity allows conceiving the product platform architecture in order to upgrade and reuse existing modules: each module can be developed independently and concurrently. Within the platform, modules can be differently combined to obtain customized products. In order to face the complexity of product customisation it is important that changes in the manufacturing process structure are coherent with changes in the product structure, balancing flexibility and efficiency (Ahmad and Schroeder 2002).

From the product design point of view, the development of products based on configurability and modularity is recognised as a winning approach in many researches, on the other end, from the manufacturing point of view, it is important the process variety management, as in example the reduction of subassembly operations proliferation when offering product variety. Several researches propose algorithms and methodologies for concurrent product and process development correlating product platform structures with assembly sequence of operations in order to consider assembly aspects during the design phase and improve process planning activities. The common standpoint is represented by the modularity of product and processes (Feng and Song 2000).

A multi-dimensional framework, that enables a comprehensive description of all product characteristics, in order to support designers in considering design and manufacturing aspects early in the product platform definition stage, it is presented in Fixson (2005). 
Agility based on modularity and configurability requires design and manufacturing technologies able to support the management of variability. From the technical point of view, the continuous advances in computer technology (both hardware and software), enhanced the support to concurrent product development tasks, but there are still several limitations that need to be addressed to efficiently support the production of customised products.

On one hand, current commercial Product Lifecycle Management (PLM) software packages offer a possible solution to support product and process information sharing, but often they fails in an efficient tracing of design changes and in particular, in the evaluation of the impact of design changes along the whole product life cycle. For this reason many companies still rely on a team of experienced people that keeps in mind product history: the problem concerns with the difficulty to explicit the tacit knowledge in order to reuse it in new design or re-design processes. The effort has to be focused on the ability of software systems to provide an information sharing environment that can support multiple viewpoints of both the product (Germani and Mandorli 2004a) and the processes related to the product lifecycle. This aspect is vital for the creation of an agile design environment, able to support change prediction.

\section{The agile management of the design process}

\subsection{Proposed approach}

A large part of industrial products are situated in the spectrum between full modularity and full integration. While in full integrated products relationships between functional and physical structures are hard to identify and configuration is difficult to achieve, modular products can facilitate the agile product development. In the present research, we are focused on products characterized by full modularity. 
The product platform characterising a full-modular product can be schematically represented by a graphical network of modules linked by a set of connections that represent constraints among the modules properties. Different relationships among the modules can represent both design alternatives and also different production solutions; hence they define different product families and production lines related to the product platform.

Several types of data can be related to the different modules that define the product platform structure: functions implemented by each module, sequences of operations required to integrate different modules, manufacturing information; etc.

In order to introduce agile concepts since the feasibility phase of design, we propose the definition of a virtual engineering framework able to integrate the product platform model, in order to represent the modular product structure, and an extended virtual prototype, able to incorporate and relate to each other the data required to represent the real physical structure of the product. The extended virtual prototype has to collect information elaborated in a synergic way by different computer based design/manufacturing support tools that manage aesthetic aspects, structural aspects, environmental aspects and so on.

Furthermore, the product platform model not only represents the modular structure of the product, but also it has to correlate each module to the manufacturing processes involved in its production. The aim of such a structure is to represent the relationships among the modules and between each module and the related production flow. In this way the product configuration management and the impact evaluation of design changes can be successfully performed.

The proposed solution based on the dual structure (the product platform and the extended virtual prototype) can allow the efficient exchange of data, the formalization of design practices into geometrical and non-geometrical rules, the collection and the retrieving of information useful for the design processes. 


\subsection{The virtual engineering framework architecture}

The virtual engineering framework architecture is based on a multiple level representation of the virtual prototype, coupled with the modular product platform. Analysis and simulation models and data are linked to the different levels of the virtual prototype. The virtual prototype and the product platform are directly related thanks to their geometric properties. Additional relations between them are set through non geometric properties and relations, stored in appropriated databases, as shown in figure 1.

Figure 1. The agile virtual engineering framework architecture.

It is worth to notice that designers and engineers use different types of CAD systems to develop design solutions. 3D CAD models are nowadays one of the preferred modes to represent design outcomes: by taking advantage of these models, it is possible to perform different analysis and simulations, and to communicate ideas in a cooperative environment.

CAD models allow representing geometric properties, dimensional parameters and constraints of product components and assemblies. Best practices for the use of CAD-based systems suggest to organise the virtual model accordingly to the structure of the physical product: components are modelled as parts, relationships are set in order to realize sub-assemblies corresponding to sub-groups and groups. The final assembly represents the complete product structure.

The geometrical information contained into the virtual model can be used, together with additional process-related information, to perform simulations and analysis, thanks to the different available computer-based tools (i.e. CAM, FEA, CAE, LCA, LCC, etc.). 
The aggregation of the geometrical information with the additional processes parameters, as well as the simulation and analysis results, define the virtual prototype.

In order to achieve a full integration among the modelling, simulation and analysis tools along the whole design process, the virtual prototype is structured on multiple levels, able to represent different points of view about the product model. In this context, multi view is intended as the possibility to shift among the multiplicity of information (geometrical and non-geometrical attributes, aesthetic, material, manufacturing processes information, etc.) encapsulated within the virtual prototype. The virtual prototype is then linked to the product platform through some of the specific properties that define the product platform modules.

The aim of the product platform is the agile management of the product in terms of product functions. The product platform represents functional, technical, production and environmental information organised in terms of product modules.

Figure 2. The product platform representation.

Each functional module is defined by a name and a set of properties. Different properties of the same module can be related through intra-module relations, as inter-modules relations are used to relate properties belonging to separated modules, as shown in figure 2. Properties and relations are stored into appropriated databases.

Both properties and relations are defined by a set of attributes, including name, category, type, value, units, range and notes. Examples of properties and relations are summarised in table 1.

Table 1. Definition of modules properties and intra and inter modules relations. 
Among the properties, we define the Supply Chain/Production properties that represent the manufacturing processes required to realize the physical structure of the module. Supply Chain/Production relations link geometric properties with production properties, providing the design constraints that drive the product model configuration (i.e. the shell curvature or its thickness depends from the technology used to realize it, the type of thermoformed film coatings is influenced by the shell materials compatibility, etc.).

When a design change is required, the proposed agile framework is able to identify which modules are affected by a functional or technological variation.

When a change occurs at the functional level, the links to the virtual prototype allows locating the corresponding parts or subassemblies, which should be modified. The virtual prototype can then be used to manage simulations and optimise the design solutions according to the whole set of information provided by the involved modules. The results of the performed analysis are then collected into the corresponding modules and the impact of changes can be estimated.

When a change occurs at the manufacturing level, (i.e. process is re-engineered in order to satisfy new emerging requirements, such as reducing time to market while improving customisation and to improve the environmental performance of the whole product life cycle), the product platform is used to identify the modules engaged by the new production process. Designers add new properties and relations in order to take into consideration manufacturing modifications into the modular platforms. According to new specifications the virtual model can be reconfigured by modifying geometrical parameters and the impact of changes assessed in the product platform.

\section{The test case in the wellness product field}




\subsection{Industrial context}

In order to validate the concepts underlying the proposed approach and assess the effectiveness of the agile framework architecture, an industrial case, related to the injectionmoulding field, has been analysed to verify its applicability for a rapid product reconfiguration, preserving the benefits of mass production.

Injection moulding is an important manufacturing process for a vast amount of industrial applications and its efficiency in terms of time and material exploitation. A major cost with a part to be moulded lies in the mould design and its operation, which are greatly influenced by certain design decisions making in the part design process. Thus, it is important to establish a link between part design and mould design that allows part designers to make design decisions that do not adversely affect mould design (Chan et al. 2003).

In this field many attempts have been made to automate the mould design process by capturing experience and knowledge of engineers in the field, as reported in (Mok et al. 2001), (Yammada et al. 2002) and (Germani et al. 2004b), and developing "intelligent" design software systems. In (Gunendran and Young 2006) it is presented an approach to support flexible integration between multiple views. A framework is proposed to capture the combination of information and knowledge in two separate but related layers. Literature overview provides the requirements for developing our proposed information management platform able to integrate software tools and design knowledge to support the feasibility analysis in injection moulding application for bathtubs.

The industrial partner of our research is a big Italian company, leader in the wellness products design and production. In the today market, wellness products are high quality sanitary ware products (showers, whirlpool bathtubs, equipped columns, steam saunas and multifunction 
and fitness corners), integrating several additional functions like aromatherapy, chromotherapy, hydromassage, ultra sound massage.

Bathtubs are currently realised by thermoforming acrylic sheets: this process implies several problems related to costs, environmental impact and product variability. A possible solution is found in the adoption of the injection moulding technology in combination with thin film coatings to realize the central body of the bathtubs (shell). This transformation implies a reengineering of the whole manufacturing process. Changes in design affect production (customisation implies modular moulds and the replacement of the thermoforming process), otherwise, changes in manufacturing needs variations of the product shape and of design solutions (optimisation of the bathtubs shell non uniform thickness and the reinforcing ribs creation).

The design process of wellness products highly depends on the designer's ability to investigate the consumers' preferences and lifestyles and translate them in aesthetic and functional specifications. Several aspects contribute to the definition of the product shape: aesthetic and functional requirements, the evolution taste, marketing requirements, ergonomic satisfaction, manufacturing and technological constraints, environmental normative standards, etc. All products are the result of a set of aesthetical and technological features such as wood facings, glass panels, plastic shells and the line of taps and additional functions. As the consumers' requirements change, they may be different in size, shape, materials, manufacturing processes, technological components and additional functions. Thermoforming is the more diffuse technology used to manufacture bathtubs and whirlpools. The thermoforming process, in general, is widely used in manufacturing industry to produce shaped plastic sheets for consumer products. The process involves draping a heat-softened plastic sheet onto the surface of a thermoforming mould. When the plastic sheet cools down, 
it takes up the shape of the mould. It allows producing thin-walled parts with large areas, using relatively inexpensive, single-sided tooling.

In the bathtubs production, it is worth to notice that the use of thermoforming implies the use of reinforcing supports to improve the structural performance, and additional costs due to manufacturing operations such as grinding, trimming, and of rejects disposal. The PMMA (polymethylmethacrylate), generally, is used to realize the plastic sheet. The reinforcing support is realized by spraying resin and fibreglass reinforcement over the bathtubs shell. On the bottom the shell is also reinforced by a wood sheet (Figure 3). Air emissions and energy use in the reinforcing process are difficulty environmentally sustainable and the bathtubs walls are difficulty recyclable because the resin strictly adheres to the plastic sheet.

The product features variability, required to satisfy the specific market needs in according to the product customisation, is extremely limited due to the manufacturing process constraints, described above. The industrial partner aims to improve the product parts reuse, using recycled materials, eliminate the spraying process from the manufacturing stages and, mainly, improve the product quality by customizing the products colours and reducing manufacturing cycle time. Besides, the process has to be oriented towards a sensible reduction of product cost.

Figure 3. Bathtub manufactured in thermoforming and related reinforcements. The left figure shows a picture of the thermoforming bathtub; the right figure represents the main layers of the bathtub's shell.

Agile processes are needed to support the required customisation and productivity. Injection moulding provides flexible productive process instead of thermoforming sheets as it allows manufacturing complex topological shapes with large dimensions, reusing recycled polymers 
in order to improve the product eco-sustainability and moulding ribbing on the bathtubs walls to improve the structural performance in place of the traditional reinforcing resin layer. The product recycling can be also performed: the new solution allows to cold work. Metallic supports and assembly accessories and the polymeric parts can be separated during the product disposal.

Finally, the manufacturing cycle time can be strongly reduced than to the intrinsic characteristics of injection moulding if compared with the thermoforming. In order to manage the changeability and customisation, injection moulding is integrated with film coatings: the resulting product can assume the aesthetic aspect required by the customer and, simultaneously, the desired low cost can be maintained. However, several critical aspects have to be considered and investigated: the technology has not yet been used in the specific field under investigation because the high initial investment and start-up costs require high production rates that difficultly can be achieved for wellness products. As the mould dimensions increase, the tooling needs of high pressure to inject the polymer into the hollow mould cavity. Therefore, incomplete filling, flaws and other finishing faults may be contained: the final quality may be not as high as required for aesthetic products. In this context it is necessary to evaluate different moulding technologies and to study the proper machine parameters to achieve the above-mentioned tasks.

Finally, in order to choose the material to realize the film coating, we take into consideration the following aspects: the adherence between the film and the plastic used to mould the bathtub, the resistance of the film to the high temperature and pressure of the injection moulding, the abrasion resistance of the film, the mar resistance (resistance of the film to the damages when subjected to the conditions for the normal use such as solvent and scratch resistance, etc.). 
All requirements and technologies limitations and constraints can be taken into considerations into the properties and relationships between modules in the proposed virtual engineering framework.

\subsection{Agile design of bathtubs}

The configuration of bathtub design in order to meet manufacturing changes and guarantee product variability starts from the creation of the product platform and the links between the recognized modules and the production flow. The functional analysis results in the following modules: the water flow, aiming at transporting water within the bathtubs shell, allowing water disposal and creating hydromassage if activated with the air flow module, the user interface for program selection, the check temperature and water level, the electricity flow, the heat converter for converting electricity into heat in order to maintain the water hot, the ultrasound generator, the signal dispatch, the structural unit to support both aesthetic and plumbing components, the body envelope and the external cover. We mainly concentrate on the manufacturing flows of operations to realize the three last modules that are affected by the production change. Proper geometric and non geometric properties and relationships between modules are set in order to manage changes propagation in the product platform and collect the necessary information to drive bathtubs configuration.

A 3D CAD model has been created in order to represent physical components realizing the functional modules. The organization of the virtual prototype into parts, sub-assemblies and assembly reflects the structure of the physical product and of the manufacturing operations flow. Links between the virtual prototype parts and the product platform modules are established in order to allow identifying which components are affected by changes when the product platform is reconfigured. 
Suitable rules have been set to extract the right model information necessary for the structural and manufacturing simulations. These rules involve geometry simplification, mesh parameters, loads and constraints positioning and types. Rules allow the creation of the multiview virtual model: each single view can be used to perform different analysis.

The manufacturing simulation is the injection moulding process. The cost and the environmental performance estimations are performed thanks to the automatic analysis of the virtual prototype (volume, area, thickness, materials) and the interrogation of the nongeometric attributes linked to the virtual model and stored within the database. Previous research work has deeply investigated the opportunity to perform LCA thanks to the automatic extraction of geometric and non geometric information from the virtual prototype (Germani et al. 2005)

Once a product modification is required due to the emerging manufacturing needs, the product platform identifies which modules are affected by modifications. The virtual model automatically highlights the product parts influenced by variations and proper information are extracted to perform the four types of simulations that are subsequently activated. Results are then collected as properties into the database and migrated into the product platform. The software system runs and the results consist into the set of design modifications necessary to meet the new requirements.

\subsection{Experimentation}

The design tools used to realize the virtual prototype and the analyses are three different commercial software packages in order to perform the CAD modelling, the structural verifications, the manufacturing simulations and the Life Cycle Assessment (LCA) respectively for cost estimation and environmental performance evaluation. The experimentation interested a specific bathtub model that is used in two different commercial 
configurations: bathtubs with (Figure 4a) and without panels (Figure 4b). In the first case a metallic frame supports the bathtub. In the second one, the bathtub directly rests on the floor and on lateral walls that have the same structuring function of the frame.

The polymeric material used to test the structural performance of the injection moulded bathtub is OROGLAS 20I, with the following mechanical properties $\mathrm{E}=1.71391 \times 10^{9} \mathrm{~N} / \mathrm{m}^{2}$, $v=0.3, \rho=1160 \mathrm{Kg} / \mathrm{m}^{3}$. The choice of an acrylic polymer with high aesthetic properties is due to the fact that it is possible to adopt transparent film coatings.

Three different configurations have been investigated: a bathtub with a constant thickness (a), a bathtub with a constant thickness and a supporting rib structure (b) and a bathtub with a variable thickness without a rib structure (c).

Figure 4. The CAD models of the bathtub under study. Figure 4a represents the CAD models of the bathtub's shell with the metallic frame; Figure $4 \mathrm{~b}$ represents the CAD model of the whole bathtub with lateral panels

In order to compare the three different solutions a virtual prototype is realized within a feature-based CAD system. The different required configurations can be obtained by modifying the design parameters.

The proposed framework has been used both to identify the best design solution and materials to realize the shell and the coating and to compare the achieved solution with the traditional one. Proper relationships have been set to link geometric properties with production properties providing design constraints driving the model configuration once a change occurs. Examples of constraints are: inclination of lateral walls, curvature radii, position and dimensions of accessories and map of thickness variability. Properties are also related to non geometric 
attributes: material characteristics, suppliers, commercial components cost, manufacturing cycle of different components usable for the bathtub assembly, characteristics of the moulding machines, etc.. The resulting virtual model, as the sum of the geometry and the structured non-geometric information, becomes the basis for managing the different performed analyses and driving the new product configuration.

The multi-view virtual prototype allows the automatic extraction of data for structural and manufacturability simulations (i.e. parameters of meshing algorithms). Loads and constraints for the structural analysis, according to the normative, are parameterised and are automatically applied on the new meshed model. Two examples are reported (Figure 5): a uniformly distributed load $\left(1500 \mathrm{~N} / \mathrm{mm}^{2}\right)$ on the base plane (left) and a uniformly distributed load $\left(1000 \mathrm{~N} / \mathrm{mm}^{2}\right)$ on the lateral edge (right).

Figure 5. Examples of the structural analysis results in terms of displacements. Figure 5a shows the deformed model of solution (b) in the case of uniform loads put on the shell. The maximum displacement is $3,34 \mathrm{~mm}$; Figure $5 \mathrm{~b}$ shows the case of uniform loads put on the bathtub's edge in situation (c). The maximum displacement is $0,38 \mathrm{~mm}$.

In parallel, a CAE system is used to simulate the injection moulding process to set proper manufacturing parameters and estimate the aesthetic quality and mouldability of the three different design solutions in order to reduce risks of investments. In Figure 6 the cooling channels distribution and the filling time results are reported for the specific case study (c).

Figure 6. The simulation of the mould flow process. Figure 6a represents the model of the cooling channels distribution; Figure $6 \mathrm{~b}$ shows the filling time results. 
On the other hand a list of formatted data is exported to the LCA tool for performing cost and environmental analysis. Analyses have been performed to compare bathtubs realized by thermoforming sheet and injection moulding and to identify which processes have a deep environmental impact. Some estimation metrics are $\mathrm{CO}_{2}$ emissions both in the working area and in air, materials reuse, carcinogens emissions, climate change impact, etc.

Figure 7 shows the result of the LCA analysis for the thermoformed bathtub situation. The environmental performance is represented as a processes network (Figure 7a) where for each block it is reported the resulting impact and as histograms (Figure 7b).

Figure 7. Examples of output data of the LCA analysis for the situation (c). Figure 7a represents a simplified network of all manufacturing operations under study; Figure $7 \mathrm{~b}$ shows two examples of environmental impact markers.

LCA results are reported in table 2.

The manufacturing process of the solution (c) consists at first in the heating and forming of the film and then in the insertion of the preformed film into the injection cavity where the resin from the mould melt-bonds with the preformed shell. The film is permanently integrated into the finished part.

First experimental tests on different polycarbonate films have been performed in order to verify the real applicability of the achieved design solution. Three films with different thickness $(0.125,0.250,0.375 \mathrm{~mm})$ and technical performances are subjected to injection mould temperature compatibility, chemical, abrasion and UV resistance tests. The lower sheets shows both problems of grip between the film and the polymeric material casting and a crosswise crack while tests on the third sheet $(0.375 \mathrm{~mm})$ show better results. (Figure 8$)$ 
Figure 8. Examples of experimental tests results. The last on the right is the polycarbonate sheet with 0.375 thickness.

\subsection{Results discussion}

Once the different simulations have been performed and verifications yielded good results according to normative standards; further experimental tests on the use of film coatings have been planned. The considered manufacturing condition is recycled polymer injection moulding over thermoformed film. This solution has several advantages: improvement of ecosustainability of process/product for the use of recycled materials, for the elimination of reinforcing resin spraying process, for the opportunity to disassembly the whole product at the disposal, reduction of manufacturing costs for the elimination of reinforcing and trimming processes, for the removal of the reinforcing wood board and for the reduction of assembly costs (several metallic accessories are incorporated within the mould), reduction of manufacturing time for the elimination of resin stoving time and for the reduction of assembly operations.

In order to qualify design process improvements by means of the application of the proposed agile approach, performance measure are essential. A list of process metrics has been established to evaluate the effectiveness of the achieved solution (Table 2) in terms of:

- manufacturing time savings that depends from the cycle time;

- impact rate that decreases as manufacturing operations producing toxic emission in air and water are substituted with more eco-sustainability processes;

- degree of product customization that measures how much the product design answers to the customer changing needs. The degree increases in accord with the ability of the 
manufacturing process to realize different customized products without additional costs;

- structural performance is better as the shell is able to carry increasing loads while optimizing its sections.

- cost savings, manufacturing time savings are directly proportional quantities. But costs savings depends also from the time necessary for bathtubs re-engineering.

Table 2. Results of the evaluation of the different analysed solutions compared with the traditional thermoforming process.

It is worth to notice that solution (c) is the best in terms of time and cost savings, of reduction of the whole environmental impact and finally of the structural performance.

\section{Conclusion}

This paper describes the main features of proposed virtual engineering framework architecture to support the agile design of modular products. It is based on multi-view virtual prototypes linked to a product platform able to manage both process and product information. The virtual prototypes are used for structural, manufacturing, costs and environmental performance evaluations. Knowledge databases allow sharing data within the whole information management platform: analysis results are collected into the product modules properties while intra and inter modules relations guarantee the evaluation of changes propagation. The product platform allows the identification of the design modifications to meet the specified requirements as it contains both geometrical and non geometrical information. 
The main proposed novelties regard with: a) the opportunity to map manufacturing and design information thanks to the adoption of a multi-view product model representation structured according to the product platform, b) the overcoming of the well-known difficulties to analyse different design alternatives before detail and embodiment design start and, subsequently, to configure the possible solution coherently with the performed evaluations results, to take into consideration the impact of changes on the whole product life cycle.

The proposed platform matches agile strategies and Information Technologies to support exchange data, information management, modular products configuration, etc. in order to create a structured framework for the agile product development.

A practical example has been illustrated where the framework has been successfully applied for the agile product development and the re-engineering of the manufacturing process. A design problem from the wellness products field has been chosen as meaningful test case as it requires a flexible production process to implement the mass customization paradigm while reducing costs and improving the environmental performance. To configure the optimal design solution a virtual prototype model has been realized, the product platform structured and linked to the manufacturing flow, design and production information have been properly structured within the modules, used to define the rules for the creation of multi-view product models subjected to different simulations. Results are used to evaluate the impact of the achieved configuration for satisfying the specific customer requirements.

To verify the efficiency and effectiveness of the proposed framework, three different bathtub's solutions have been studied. The chosen solution (c) results shows a possible 30\% cost saving and a good process flexibility to respond at the unpredicted emerging market needs. Furthermore, the environmental impact assessment showed a sensible improvement thanks to the elimination of the resins and the minimization of metallic components. 
Future work in the industrial context deals with: the design of the production layout in order to transform the tradition flow of operations optimising components movements and entering new injection moulding machines, the detail design of modular moulds in to satisfy a wider number of configurations, and, finally, the design of the machine for integrated the film coating into the mould. Furthermore, much work has to be done in order to implement the resulting manufacturing process and a deeper analysis of the investments for a take back and recycling system is required

On the other side, the application of the proposed framework shows some limitations: the complexity to manage the continuous transformation of the virtual prototype during the whole design cycle, from conceptual to detail models and therefore, to take into considerations the different levels of abstraction of the product platform, the difficulty to automatically fulfil modules properties and to explicit the design knowledge in terms of rules and relations between the modules properties.

Future research work will be concentrated on the improvement of the knowledge databases by adding several manufacturing processes in order to extend the applicability of the framework to other industrial context, on the implementation of the rules to link the product platform with the multi-view virtual prototype for realizing a software tool and finally on the elaboration of an additional module to perform feasibility analyses during the whole product development.

\section{References}

Ahmad, S. and Schroeder, R.G., 2002. Refining the product-process matrix. International Journal of Operations \& Production Management, Vol. 22(1), 103-124. 
Chan, W.M., Yan, L., Xiang, W. and Cheok, B.T., 2003. A 3D CAD knowledge-based assisted injection mould design system. International Journal of Advanced Manufacturing Technology, Vol.22 (5-6), 387-395.

Chen, Y.M. and Liu, J.J., 1999. Cost-effective design for injection moulding. Robotics and Computer-Integrated Manufacturing, Vol.15, 1-21.

D'Aveni, R.A., 1995. Coping with hypercompetition: utilizing the new 7S framework, Academy of Management Executive, Vol. 9, 45-60.

Feldhusen, J., Macke, N. and Bungert, F., 2006. Increasing the efficiency of product development processes with automated simultaneous engineneering (aSE). CD-ROM Proceedings of the TMCE 2006, ed. by Horváth I and Duhovnik J, Lubljiana (Slovenia)

Feng, S.C. and Song, E.Y., 2000. Information modeling of conceptual process planning integrated with conceptual design. CD-ROM Proceedings of the $5^{\text {th }}$ Design For Manufacturign Conference, ASME Design Engineering Technical Conceferences, Baltimore, Maryland, 10-13 September.

Fixson, S.K., 2005. Product architecture assessment: a tool to link product, process, and supply chain design decisions. Journal of Operations Management, Vol. 23, 345-369.

Germani, M. and Mandorli, F., 2004a. Self-configuring components approach to product variant development, AIEDAM - Artificial Intelligence for Engineering Design, Analysis and Manufacturing, Special Issue: Platform Product Development for Mass Customization, V. 18 (1), 41 - 54.

Germani, M. and Mandorli, F., 2004b. A CAD/CAM System for the Concurrent Design and Manufacturing of Injection Moulds. International Journal of Agile Manufacturing, Vol. 7 (1), 1-8. 
Germani, M., Mandorli, F. and Mengoni, M., 2005. Multi-Level Product Model to Support the LCA Use in the Early Design Phase. CD-ROM Proceedings of International Conference on Engineering Design, Melbourne, 15-18 August.

Gunasekaran, A. and Yusuf, Y.Y., 2002. Agile manufacturing: a taxonomy of strategic and technological Imperatives. International Journal of Production Research, Vol. 40(6), $1357-1385$.

Gunasekaran, A., 1998. Agile manufacturing: enablers and an implementation framework. International Journal of Production Research, Vol. 36 (5),1223-1247.

Gunendran, A.G. and Young, R.I.M., 2006. An information and knowledge framework for multi-perspective design and manufacture. International Journal of Computer Integrated Manufacturing, Vol. 19 (4), $326-338$.

Lomas, C.D.W., Wilkinson, J., Maropoulos, P.G. and Matthews, P.C., 2006. Implementing Digital Enterprise Technologies for Agile Design in the virtual enterprise. CD-ROM Proceedings of 3rd International CIRP Sponsored Conference on Digital Enterprise Technology, Setubal, Portugal.

Maropoulos, P.G., 2003. Digital Enterprise Technology - defining perspectives and research priorities. International Journal of Computer Integrated Manufacture, Vol. 16 (7-8), 467478.

Matthews, P.C., Lomas, C.D., Armoutis, N.D. and Maropoulos, P.G., 2005. Foundations of an agile design methodology. Proceedings of the International Conference on Agility ICAM 2005, Helsinki, 27-28 July, 299-305.

Mok, C.K., Chin, K.S. and Ho J.K.L., 2001. An Interactive Knowledge-Based CAD System For Mould Design in Injection Moulding Processes. The International Journal of Advanced Manufacturing Technology, Vol. 17(1), 27-38. 
Mondragon, A.C., Lyons, A.C. and Kehoe, D.F., 2004. Assessing the value of information systems in supporting agility in high tech manufacturing enterprises. International Journal of Operations and Production Management, Vol. 24(12), 1219-1246.

O’Grady, P., 1999. The age of modularity. Iowa City: Adams and Steele (eds)

Preiss, K., Goldman, S.L. and Nagel, R.N., 1996. Cooperate to compete: building agile business relationships. Nw York: Van Nostrand Reinhold ed.

Yamada, J., Chambers, T.L. and Dwivedi, S., 2002. Intelligent Tool for Plastic Injection Mould Design. In: Goncalves, Roy \& Steiger-Garcao, eds., Advances in Concurrent Engineering. Cranfield, UK: Swets \& Zeitlinger, 569-574

Ye, N., 2002. Information infrastructure of engineering collaboration in a distributed virtual enterprise. International Journal of Computer Integrated Manufacturing, Vol. 15 (3), 265273. 


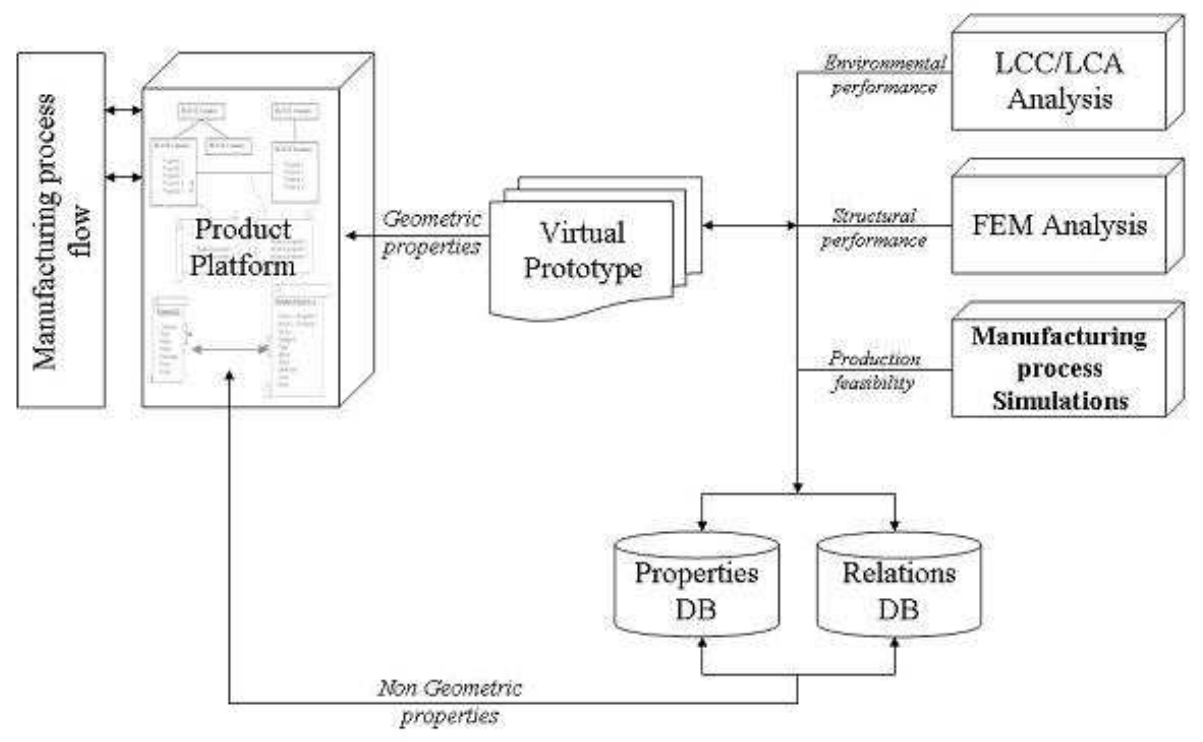

The agile virtual engineering framework architecture. $169 \times 105 \mathrm{~mm}(96 \times 96$ DPI $)$ 


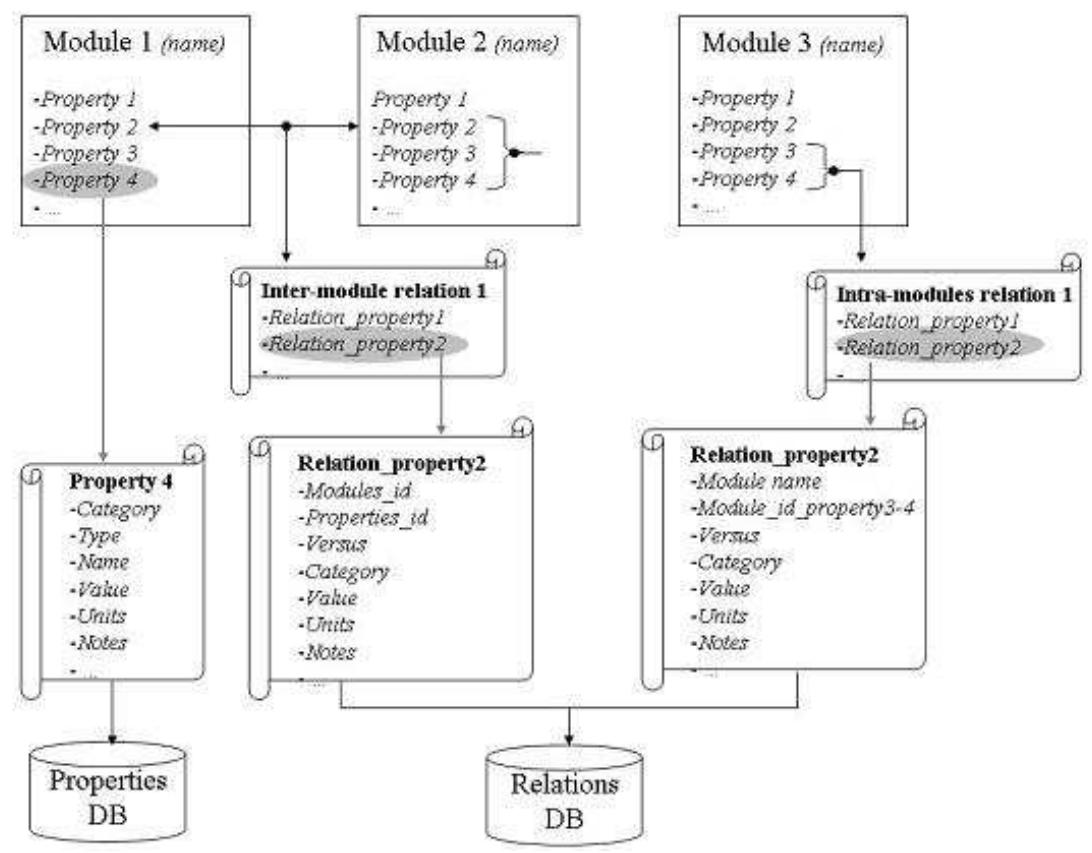

The product platform representation. $169 \times 109 \mathrm{~mm}(96 \times 96 \mathrm{DPI})$ 


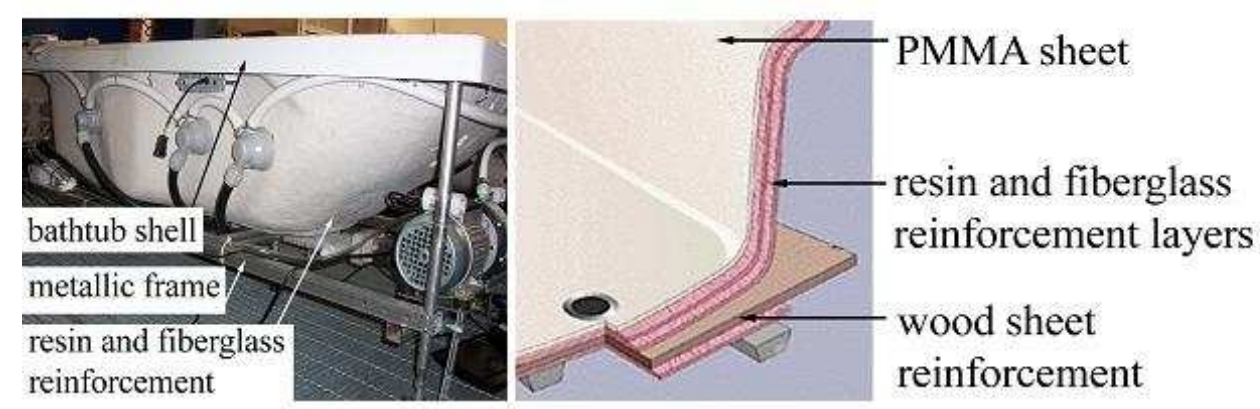

Bathtub manufactured in thermoforming and related reinforcements. The left figure shows a picture of the thermoforming bathtub; the right figure represents the main layers of the bathtub's shell. $171 \times 105 \mathrm{~mm}(96 \times 96 \mathrm{DPI})$ 


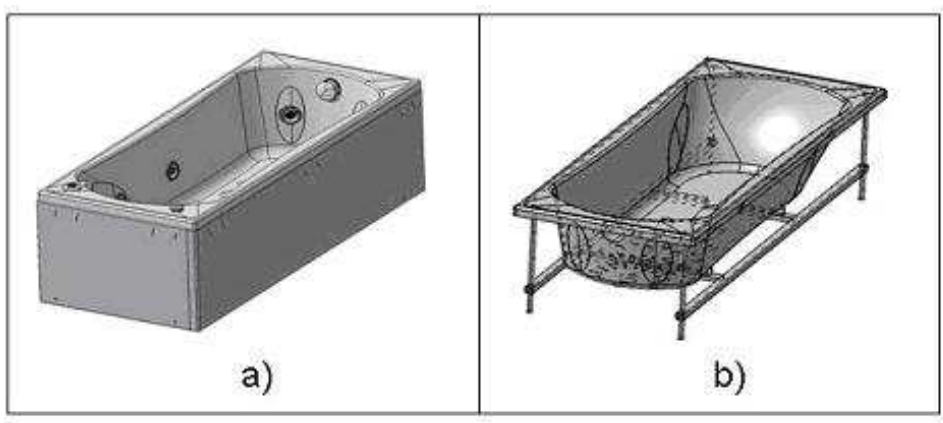

CAD models of the bathtub under study. a. it represents the CAD models of the bathtub's shell with the metallic frame; b. it represents the CAD model of the whole bathtub with lateral panels $169 \times 105 \mathrm{~mm}(96 \times 96 \mathrm{DPI})$ 


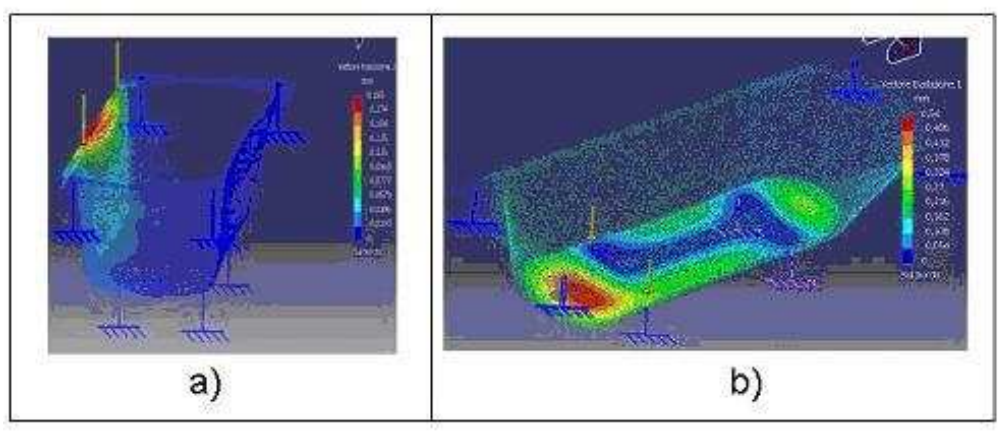

Examples of the structural analysis results in terms of displacements. Figure 5 a shows the deformed model of solution (b) in the case of uniform loads put on the shell. The maximum displacement is $3,34 \mathrm{~mm}$; Figure $5 \mathrm{~b}$ shows the case of uniform loads put on the bathtub's edge in situation (c). The maximum displacement is $0,38 \mathrm{~mm}$. $169 \times 105 \mathrm{~mm}(96 \times 96 \mathrm{DPI})$ 


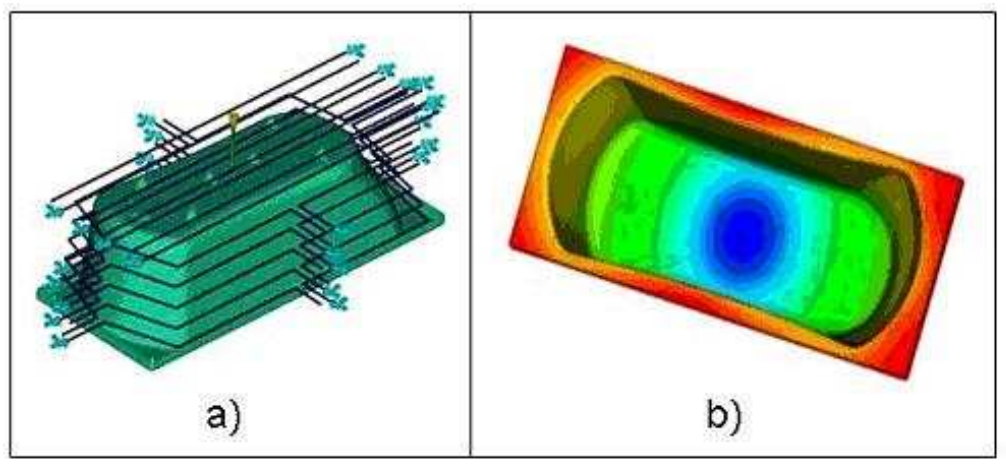

The simulation of the mould flow process. Figure 6a represents the model of the cooling channels distribution; Figure $6 \mathrm{~b}$ shows the filling time results.

$169 \times 105 \mathrm{~mm}(96 \times 96 \mathrm{DPI})$ 


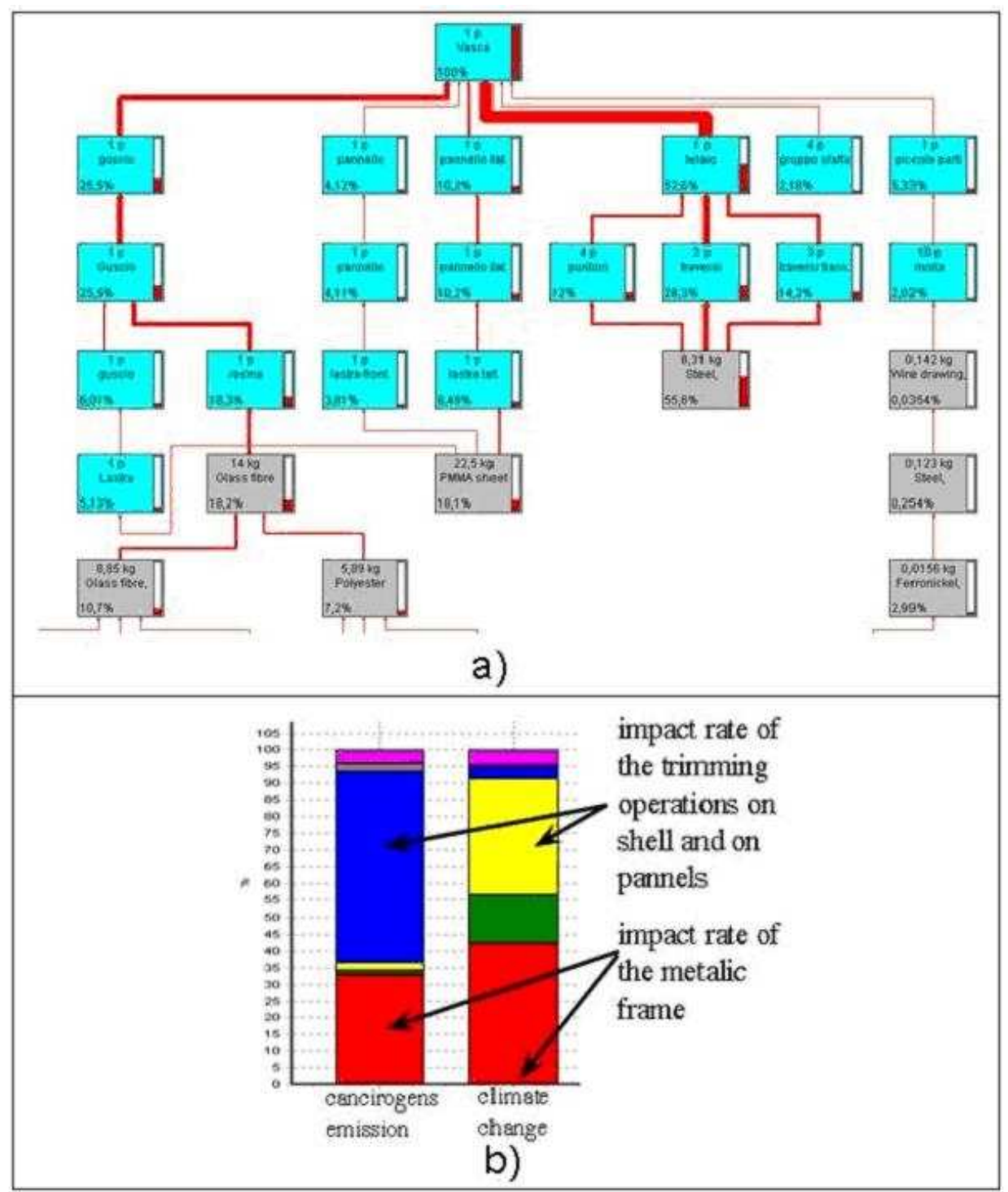

Examples of output data of the LCA analysis for the situation (c). Figure 7a represents a simplified network of all manufacturing operations under study; Figure $7 \mathrm{~b}$ shows two examples of environmental impact markers. $169 \times 192 \mathrm{~mm}(96 \times 96 \mathrm{DPI})$ 


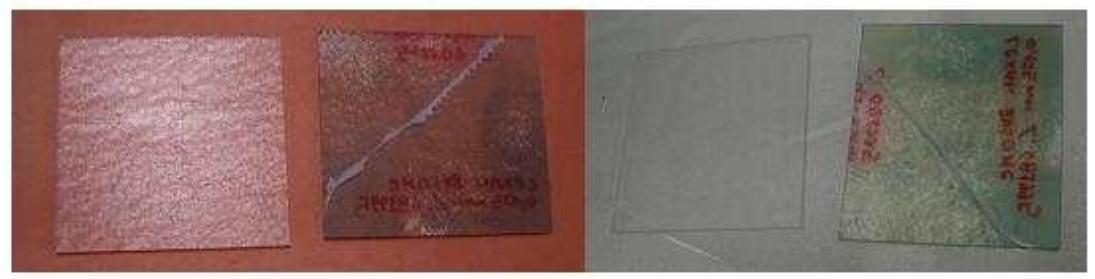

Examples of experimental tests results. The last on the right is the polycarbonate sheet with 0.375 thickness.

$174 \times 105 \mathrm{~mm}(96 \times 96 \mathrm{DPI})$

URL: http://mc.manuscriptcentral.com/tandf/tcim Email:ijcim@bath.ac.uk 
Table 1. Definition of modules properties and intra and inter modules relations.

\begin{tabular}{|c|c|c|c|c|c|}
\hline \multicolumn{3}{|c|}{ Properties } & \multicolumn{3}{|c|}{ Intra and Inter modules relations } \\
\hline Category & Type & Name & Category & Туре & Name \\
\hline \multirow[t]{3}{*}{ Competence Area } & Fluid dynamics & Referent & \multirow{3}{*}{$\begin{array}{l}\text { Physical } \\
\text { Linkage }\end{array}$} & \multirow[t]{2}{*}{ Direct } & Welding \\
\hline & Structural & Referent & & & $\ldots .$. \\
\hline & Material & Referent & & Indirect & Wiring \\
\hline \multirow[t]{8}{*}{ Geometric } & \multirow[t]{3}{*}{ Position } & Tilt & \multirow{12}{*}{$\begin{array}{l}\text { Conceptual } \\
\text { Linkage }\end{array}$} & \multirow[t]{3}{*}{ Position } & Parallelism \\
\hline & & Position & & & Perpendicular \\
\hline & & Orientation & & & $\ldots \ldots$. \\
\hline & \multirow[t]{5}{*}{ Dimension } & Width & & \multirow{4}{*}{$\begin{array}{l}\text { Technique } \\
\text { Decisions }\end{array}$} & Project Variants \\
\hline & & Thickness & & & Quantity \\
\hline & & Volume & & & Material \\
\hline & & Diameter & & & $\ldots \ldots$. \\
\hline & & Height & & Aesthetic & Colour Matching \\
\hline \multirow[t]{8}{*}{ Technical Information } & \multirow[t]{4}{*}{ Technical Parameters } & RPM & & \multirow[t]{2}{*}{ Purchase } & Supplier \\
\hline & & Frequency & & & $\ldots .$. \\
\hline & & Material & & \multirow[t]{2}{*}{ Production } & Production Lines \\
\hline & & Quantity & & & $\ldots \ldots$. \\
\hline & \multirow[t]{2}{*}{ Lay-out } & Heads number & & & \\
\hline & & Ways number & & & \\
\hline & \multirow[t]{2}{*}{ Experimental Tests } & Heating & & & \\
\hline & & Scratching & & & \\
\hline \multirow[t]{4}{*}{ Supply Chain/Production } & \multirow[t]{3}{*}{ Purchase } & Supplier & & & \\
\hline & & Cost & & & \\
\hline & & $\begin{array}{l}\text { Environmental } \\
\text { Performance }\end{array}$ & & & \\
\hline & Internal & Time & & & \\
\hline Aesthetic/Comfort & Aspect & Colour & & & \\
\hline
\end{tabular}


Table 2. Results of the evaluation of the different analysed solutions compared with the traditional thermoforming process.

\begin{tabular}{|c|c|c|c|c|c|}
\hline $\begin{array}{l}\text { Solution (a): } \\
\text { bathtub } \\
\text { realized by } \\
\text { thermoforming } \\
\text { a PMMA sheet } \\
\text { with resin } \\
\text { reinforcements }\end{array}$ & $\begin{array}{l}\text { (existent } \\
\text { solution that is } \\
\text { used as term of } \\
\text { comparison) }\end{array}$ & $\begin{array}{l}\text { The } 18,3 \% \text { of } \\
\text { the whole } \\
\text { impact is due } \\
\text { to the } \\
\text { reinforcement } \\
\text { operations. The } \\
52,5 \% \text { is due } \\
\text { to the metallic } \\
\text { accessories and } \\
\text { frame }\end{array}$ & $\begin{array}{l}- \\
\text { For new } \\
\text { emerging } \\
\text { needs a new } \\
\text { solution is } \\
\text { redesigned. }\end{array}$ & $\begin{array}{c}\text { Displacement } \\
\text { at the centre } \\
\text { of the shell is } \\
\text { about } 0,5 \\
\text { mm }\end{array}$ & $\begin{array}{c}\text { manufacturing } \\
\text { cost is about } \\
51 €\end{array}$ \\
\hline $\begin{array}{l}\text { Metrics for the } \\
\text { evaluation of } \\
\text { the achieved } \\
\text { solution }\end{array}$ & $\begin{array}{l}\text { Manufacturing } \\
\text { time savings }\end{array}$ & $\begin{array}{c}\text { Reduction of } \\
\text { the } \\
\text { environmental } \\
\text { impact (the } \\
\text { impact rate) }\end{array}$ & $\begin{array}{l}\text { Flexibility to } \\
\text { respond to the } \\
\text { market needs } \\
\text { (product } \\
\text { customization) }\end{array}$ & $\begin{array}{c}\text { Structural } \\
\text { performance }\end{array}$ & Cost savings \\
\hline $\begin{array}{c}\text { Solution } \\
\text { (b):moulded } \\
\text { bathtub with } \\
\text { constant } \\
\text { thickness and } \\
\text { supporting rib } \\
\text { structure }\end{array}$ & $\begin{array}{c}-23 \% \\
\text { (it is less than } \\
\text { (c) for the time } \\
\text { for larger filling } \\
\text { time) }\end{array}$ & $\begin{array}{l}\text { The } \\
\text { reinforcement } \\
\text { with resin and } \\
\text { Fibreglass is } \\
\text { eliminated. } \\
\text { The impact of } \\
\text { the metallic } \\
\text { accessories and } \\
\text { frame is } \\
\text { reduced to } \\
41,3 \% \text {. }\end{array}$ & $\begin{array}{c}+20 \% \\
\text { (creation of } \\
\text { customized } \\
\text { colors shells) }\end{array}$ & $\begin{array}{c}\text { Displacement } \\
\text { at the centre } \\
\text { of the shell is } \\
\text { about } 3,34 \\
\mathrm{~mm}\end{array}$ & $\begin{array}{c}-26 \% \\
\text { (manufacturing } \\
\text { cost is about } \\
37,74 € \text { ) }\end{array}$ \\
\hline $\begin{array}{c}\text { Solution } \\
\text { (c):moulded } \\
\text { bathtub with a } \\
\text { variable } \\
\text { thickness }\end{array}$ & $\begin{array}{l}-28 \% \\
\text { ( elimination of } \\
\text { resin stoving } \\
\text { time, reduction } \\
\text { of assembly } \\
\text { operations) }\end{array}$ & $\begin{array}{l}\text { It is the same } \\
\text { of solution (b) }\end{array}$ & $\begin{array}{l}+20 \% \\
\text { (creation of } \\
\text { customized } \\
\text { colors shells) }\end{array}$ & $\begin{array}{c}\text { Displacement } \\
\text { at the centre } \\
\text { of the shell is } \\
\text { about } 0,54 \\
\mathrm{~mm}\end{array}$ & $\begin{array}{c}-36,4 \% \\
\text { (manufacturing } \\
\text { cost is about } \\
32,4 € \text { ) }\end{array}$ \\
\hline
\end{tabular}

